\title{
Simulation Comparisons of Three Different Meander Line Dipoles
}

\author{
by Seth A McCormick
}

ARL-TN-0656

January 2015 


\section{NOTICES}

\section{Disclaimers}

The findings in this report are not to be construed as an official Department of the Army position unless so designated by other authorized documents.

Citation of manufacturer's or trade names does not constitute an official endorsement or approval of the use thereof.

Destroy this report when it is no longer needed. Do not return it to the originator. 


\title{
Army Research Laboratory
}

Adelphi, MD 20783-1138

ARL-TN-0656

January 2015

\section{Simulation Comparisons of Three Different Meander Line Dipoles}

\author{
Seth A McCormick \\ Sensors and Electron Devices Directorate, ARL
}




\begin{tabular}{|c|c|c|c|c|c|}
\hline \multicolumn{5}{|c|}{ REPORT DOCUMENTATION PAGE } & $\begin{array}{l}\text { Form Approved } \\
\text { OMB No. 0704-0188 }\end{array}$ \\
\hline \multicolumn{6}{|c|}{ 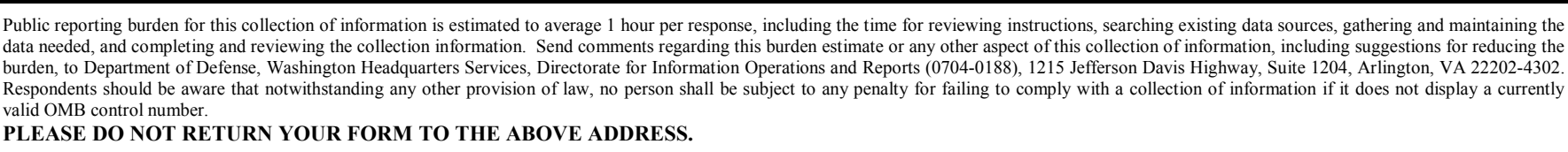 } \\
\hline \multirow{2}{*}{\multicolumn{2}{|c|}{$\begin{array}{l}\text { 1. REPORT DATE (DD-MM-YYYY) } \\
\text { January } 2015\end{array}$}} & \multirow{2}{*}{\multicolumn{3}{|c|}{$\begin{array}{l}\text { 2. REPORT TYPE } \\
\text { Final }\end{array}$}} & 3. DATES COVERED (From - To) \\
\hline & & & & & $09 / 2014$ \\
\hline \multirow{3}{*}{\multicolumn{5}{|c|}{$\begin{array}{l}\text { 4. TITLE AND SUBTITLE } \\
\text { Simulation Comparisons of Three Different Meander Line Dipoles }\end{array}$}} & 5a. CONTRACT NUMBER \\
\hline & & & & & 5b. GRANT NUMBER \\
\hline & & & & & 5c. PROGRAM ELEMENT NUMBER \\
\hline \multirow{4}{*}{\multicolumn{5}{|c|}{$\begin{array}{l}\text { 6. AUTHOR(S) } \\
\text { Seth A McCormick }\end{array}$}} & 5d. PROJECT NUMBER \\
\hline & & & & & 9017.1 .1 \\
\hline & & & & & 5e. TASK NUMBER \\
\hline & & & & & 5f. WORK UNIT NUMBER \\
\hline \multicolumn{5}{|c|}{$\begin{array}{l}\text { 7. PERFORMING ORGANIZATION NAME(S) AND ADDRESS(ES) } \\
\text { U.S. Army Research Laboratory } \\
\text { ATTN: RDRL-SER-M } \\
\text { 2800 Powder Mill Road } \\
\text { Adelphi, MD 20783-1138 }\end{array}$} & $\begin{array}{l}\text { 8. PERFORMING ORGANIZATION } \\
\text { REPORT NUMBER } \\
\text { ARL-TN-0656 }\end{array}$ \\
\hline \multirow{2}{*}{\multicolumn{5}{|c|}{ 9. SPONSORING/MONITORING AGENCY NAME(S) AND ADDRESS(ES) }} & 10. SPONSOR/MONITOR'S ACRONYM(S) \\
\hline & & & & & $\begin{array}{l}\text { 11. SPONSOR/MONITOR'S REPORT } \\
\text { NUMBER(S) }\end{array}$ \\
\hline \multicolumn{6}{|c|}{$\begin{array}{l}\text { 12. DISTRIBUTION/AVAILABILITY STATEMENT } \\
\text { Approved for public release; distribution unlim }\end{array}$} \\
\hline \multicolumn{6}{|c|}{ 13. SUPPLEMENTARY NOTES } \\
\hline \multicolumn{6}{|l|}{ 14. ABSTRACT } \\
\hline \multicolumn{6}{|c|}{$\begin{array}{l}\text { This report presents simulation comparisons between an antipodal planar dipole (resonant at } 450 \mathrm{MHz} \text { ) and } 3 \text { different } \\
\text { meander structures: square, sinusoidal, and triangular. The } 3 \text { different structures demonstrate the effect that different meander } \\
\text { trace structures can have on size reduction, gain, reflection coefficient, and bandwidth. The meanders were designed first with } \\
\text { a circuit equivalent. The results between the } 3 \text { structures show that for size reduction the square meander is the preferred } \\
\text { method at } 27.5 \% \text { but it reduces the bandwidth by } 22.37 \% \text { with a loss in matching of } 4.36 \mathrm{~dB} \text { and gain loss of } 0.26 \mathrm{dBi} \text {. The } \\
\text { sinusoidal meander shows a size reduction of } 23.04 \% \text { and a bandwidth reduction of } 12.9 \% \text { with a loss in reflection coefficient } \\
\text { by } 0.48 \mathrm{~dB} \text { and a loss in gain by about } 0.14 \mathrm{dBi} \text {. The triangular meander shows the best results for the gain and reflection } \\
\text { coefficient, while only having a size reduction of } 19.82 \% \text {. The triangular meander reduces the bandwidth by } 16.0 \% \text { with an } \\
\text { improvement in matching by } 0.69 \mathrm{~dB} \text { and a loss of gain by } 0.09 \mathrm{dBi} \text {. Ultimately, the preferred meander structure depends } \\
\text { upon the application. }\end{array}$} \\
\hline \multicolumn{6}{|c|}{$\begin{array}{l}\text { 15. SUBJECT TERMS } \\
\text { meander, planar dipole, size reduction }\end{array}$} \\
\hline \multicolumn{3}{|c|}{ 16. SECURITY CLASSIFICATION OF: } & $\begin{array}{l}\text { 17. LIMITATION } \\
\text { OF } \\
\text { ABSTRACT }\end{array}$ & $\begin{array}{l}\text { 18. NUMBER } \\
\text { OF } \\
\text { PAGES }\end{array}$ & $\begin{array}{l}\text { 19a. NAME OF RESPONSIBLE PERSON } \\
\text { Seth A McCormick }\end{array}$ \\
\hline $\begin{array}{l}\text { a. REPORT } \\
\text { Unclassified }\end{array}$ & $\begin{array}{l}\text { b. ABSTRACT } \\
\text { Unclassified }\end{array}$ & $\begin{array}{l}\text { c. THIS PAGE } \\
\text { Unclassified }\end{array}$ & & & $\begin{array}{l}\text { 19b. TELEPHONE NUMBER (Include area code) } \\
\text { 301-394-2706 }\end{array}$ \\
\hline
\end{tabular}




\section{Contents}

List of Figures $\quad$ iv

List of Tables $\quad$ iv

$\begin{array}{ll}\text { 1. Introduction } & 1\end{array}$

2. Design 1

$\begin{array}{lr}\text { 3. Simulations } & 3\end{array}$

$\begin{array}{ll}\text { 4. Conclusion } & 9\end{array}$

$\begin{array}{ll}\text { 5. References } & 10\end{array}$

Distribution List 11 


\section{List of Figures}

Fig. 1 SLDA circuit model............................................................................................2

Fig. 2 Square meandered dipole arm .......................................................................

Fig. 3 Baseline antipodal dipole..................................................................................

Fig. 4 MLDA frequency-shifted antipodal simulation models ..............................................4

Fig. 5 Reflection coefficient for frequency-shifted meanders .............................................5

Fig. 6 Realized gain for frequency-shifted meanders ....................................................6

Fig. 7 Size reduction comparisons (not to scale) .................................................................

Fig. 8 Reflection coefficient for reduced-size meanders ......................................................

Fig. 9 Realized gain for reduced-size meanders ................................................................ 8

\section{List of Tables}

Table 1 Dimensions for the frequency-shifted square meander ...........................................8

Table 2 Simulation results for the frequency-shifted meander results .................................. 9

Table 3 Simulation results for the reduced-size meanders results ........................................... 9 


\section{Introduction}

Meandering is a method by which a resonant antenna can be reduced in size to fit a smaller application. ${ }^{1}$ Because resonant antennas are directly proportional to the operating wavelength, applications that require lower frequencies but possess size limitations are challenged by the contradiction. Most common meanders use a square function as the basis for the meander line; this allows for efficient use of space as the meanders can be placed quite close to one another as long as the distance of separation between traces is not be less than the trace width (preferably slightly larger). However, continued meandering of the antenna trace introduces some detrimental effects.

The biggest negative impact is the reduced reflection coefficient that occurs when an antenna line is meandered. Each turn introduces a mutual capacitance that not only influences the resonant frequency but also the reflection coefficient, making it difficult to design an efficient meander as the antenna may not be able to be reduced by as much as desired without severe detrimental effects. Gain loss also occurs since with every additional turn opposing currents are introduced creating field cancelations. ${ }^{2}$ Bandwidth reduction is another problem with meandered line antennas.

The goal of this report is to design a square meander line antenna using a circuit equivalent model and compare its function to 2 other types of meander: sinusoidal and triangular. The 2 new meanders use the square meander as a template in order to maintain construction consistency. All 3 are simulated using $\mathrm{FEKO}^{3}$ and subsequently compared to determine the individual impact on size reduction (frequency shift), realized gain, reflection coefficient, and bandwidth.

\section{Design}

The circuit equivalent for the meandered dipole is a modified version of the well-known dipole circuit equivalent model. ${ }^{4}$ Figure 1 shows the standard circuit model for the straight line dipole antenna (SLDA) that will be used for the meander line dipole antenna (MLDA). ${ }^{4,5}$ Figure 2 shows 1 of the 2 MLDA arms with 3 meanders. In this report, a meander is defined as an individual section made of 3 additional segments. This is important to note as the equations are dependent upon the number of meanders and a different definition can result in a different answer.

$$
C_{31}=\left\{\frac{12.0674(L-2 w N)}{\log \left(\frac{2 L-2 w N}{a}\right)-0.7245}\right\} p F
$$




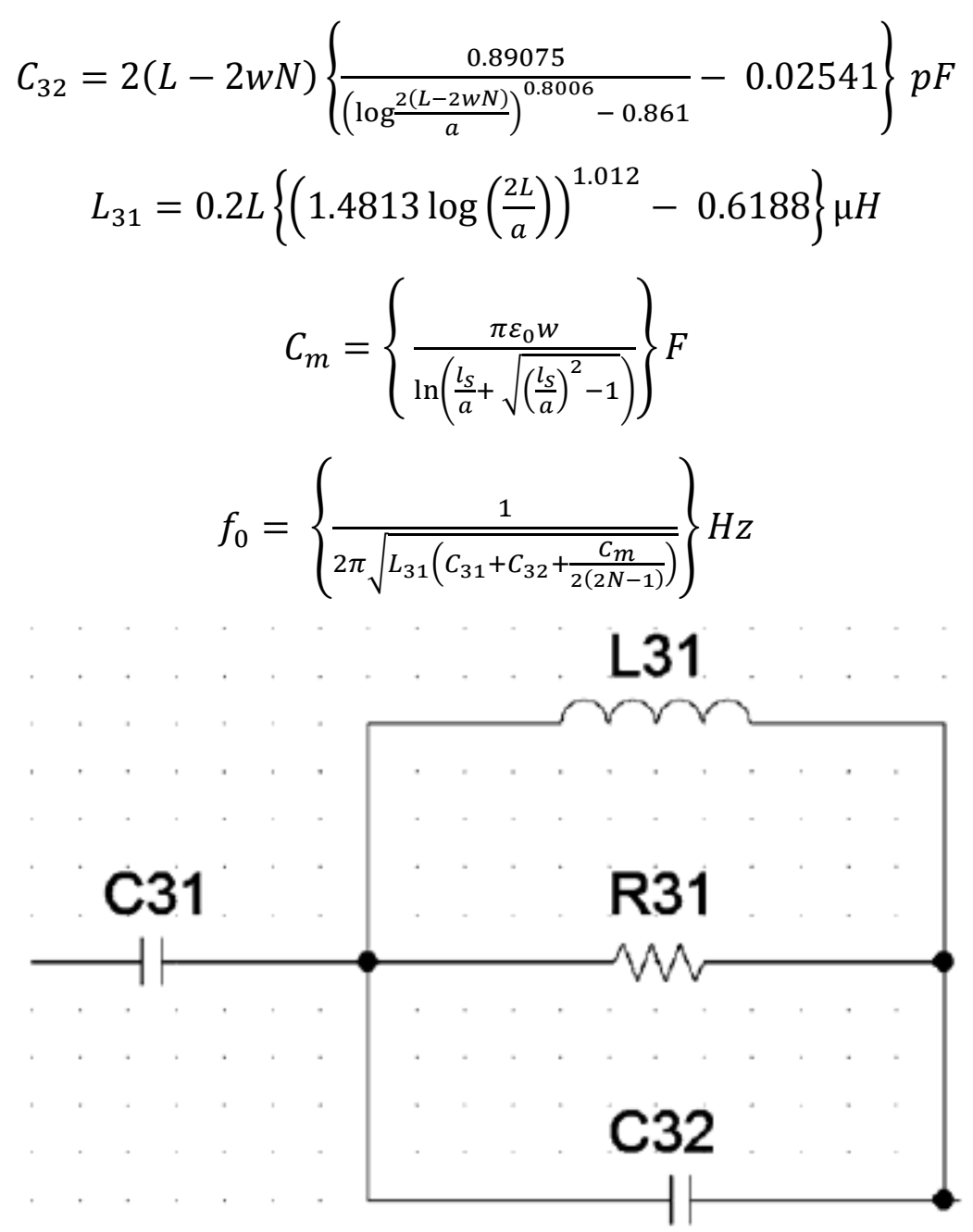

Fig. 1 SLDA circuit model

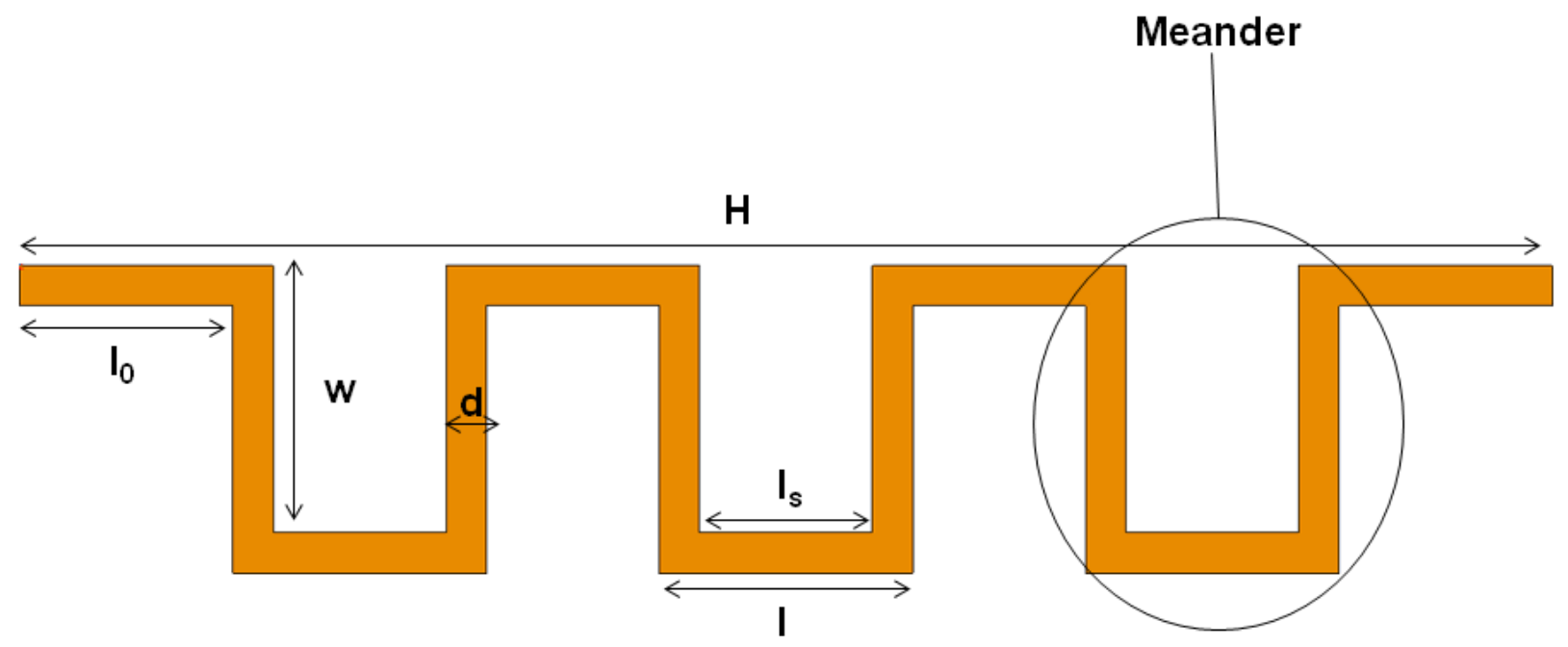

Fig. 2 Square meandered dipole arm 
Equations 1-3 are the SLDA equivalent circuit equations adapted for an MLDA, where L is the total wire length, $\mathrm{w}$ is the meander width, $\mathrm{N}$ is the number of meanders, and a is the equivalent wire radius for trace width $\mathrm{d}(\mathrm{a}=\mathrm{d} / 4){ }^{4,6}$ Equation 4 determines the mutual capacitance between the adjacent wire sections, where $1_{\mathrm{s}}$ is the spacing between the 2 parallel wires that form a meander. ${ }^{4}$ Equation 5 is the estimated resonant frequency for the MLDA. It should be noted that these equations are reasonably accurate for an MLDA whose number of meanders lie between 1 and 6 with an accuracy of less than 15\% error, providing a good start for MLDA design.

The design constraints required that the MLDA does not occupy anymore area than what is present on the baseline model's substrate. The baseline model is an antipodal planar dipole structure with a tapered micro-strip line feed; the structure and modifications were validated in a previous report. ${ }^{7}$ Due to the space restrictions, the arms of the MLDA cannot exceed $152.4 \mathrm{~mm}$ in mechanical length, and the meander width must be less than $50 \mathrm{~mm}$. Also, the spacing between the arms must not interfere with the placement of the micro-strip feed and its associated ground plane. For these reasons, the meander width was held constant at $30.42 \mathrm{~mm}$ with only the meander lengths being free to change. Both the triangular and sinusoidal meanders used the square meander as a template in order to maintain relative consistency with the definition of a meander.

\section{Simulations}

The simulations were done using computer-aided design (CAD) $\mathrm{FEKO}^{3}$ as the design and simulation tool. Figure 3 shows the baseline antipodal dipole. The MLDA simulation models are shown in Fig. 4. Each model maintains the same antipodal planar structure as the baseline model and uses a micro-strip line that has been tapered to achieve a 50- $\Omega$ impedance match; the ground plane is also reduced in width. Each model is fed with an edge feed to maintain consistency with the baseline model. It is important to note that the trace width of the triangular meander is thinner than the baseline trace width by a factor of 1.41 due to the trace being drawn along the diagonal. 


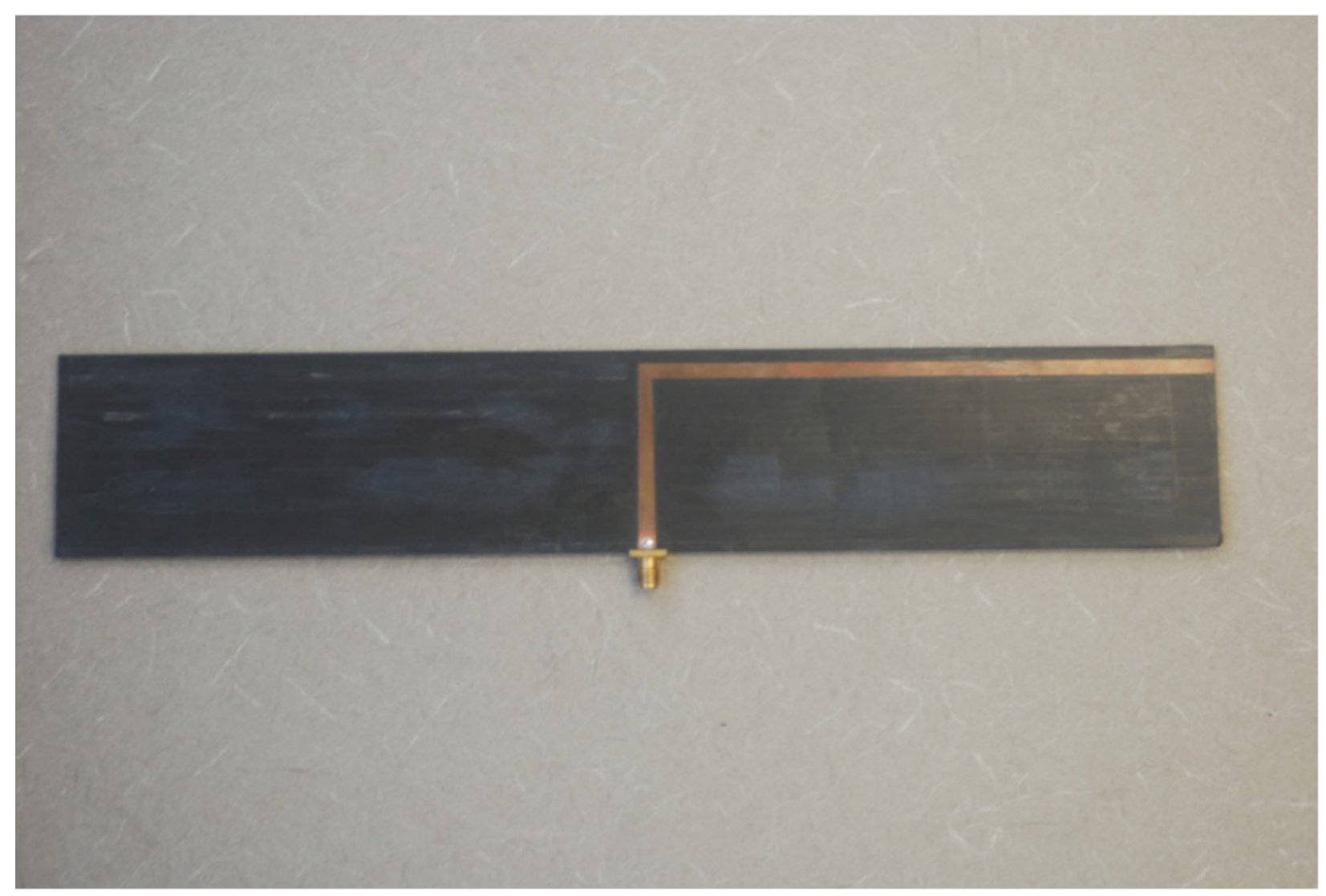

Fig. 3 Baseline antipodal dipole
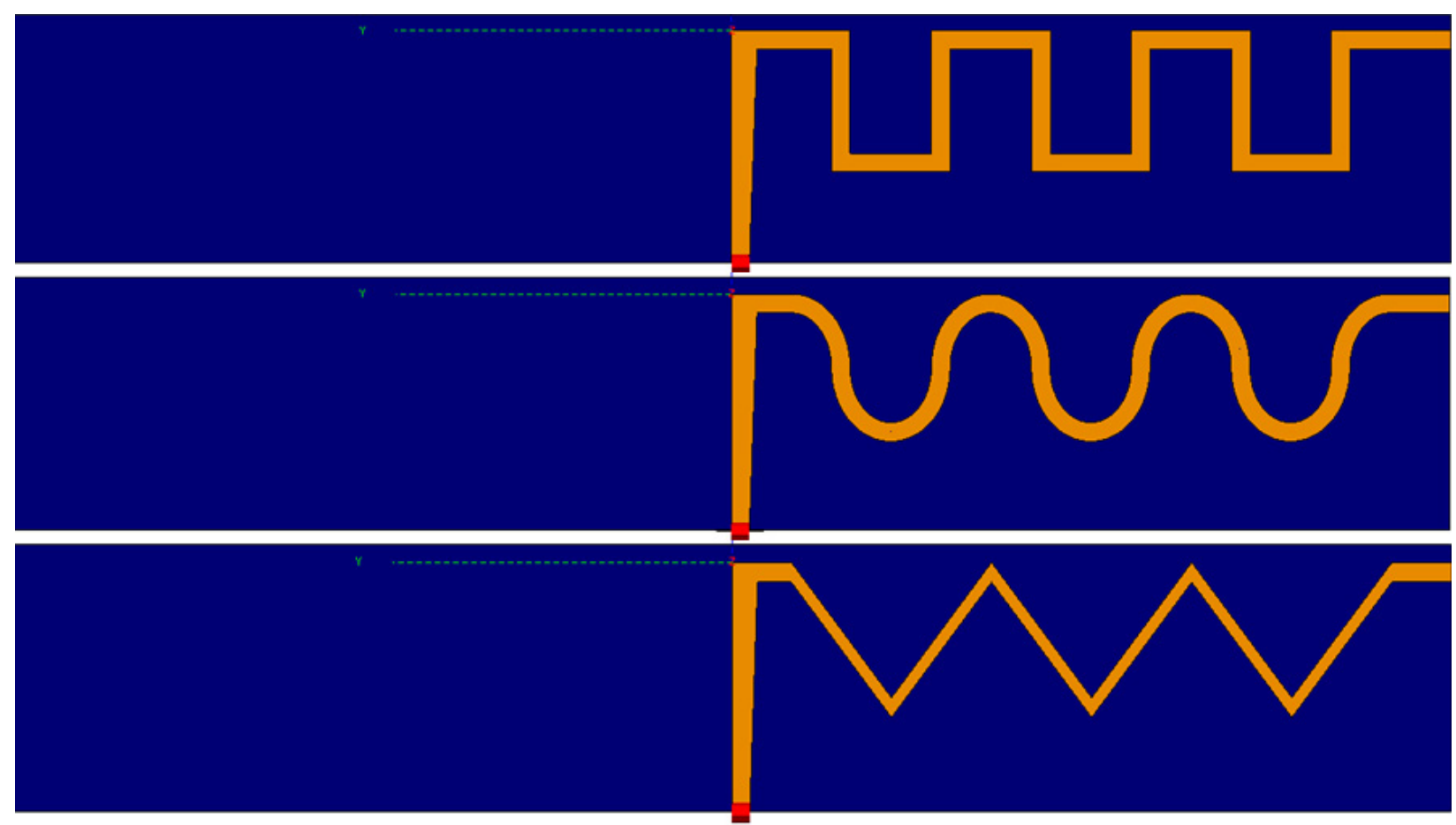

Fig. 4 MLDA frequency-shifted antipodal simulation models 
Figures 5 and 6 show that the square meander results in the largest frequency shift at $27.5 \%$, due to the fact that more space is being occupied on the dielectric, but has a reduced reflection coefficient (6.00 dB), severe loss of bandwidth (53.39\%), and decreased realized gain (0.36 dBi). Field cancelations due to opposing current flow direction along the meander widths explain the decreased realized gain. The reductions in bandwidth and reflection coefficient are attributed to the increase in inductance due to a longer trace and the mutual capacitances between meander sections.

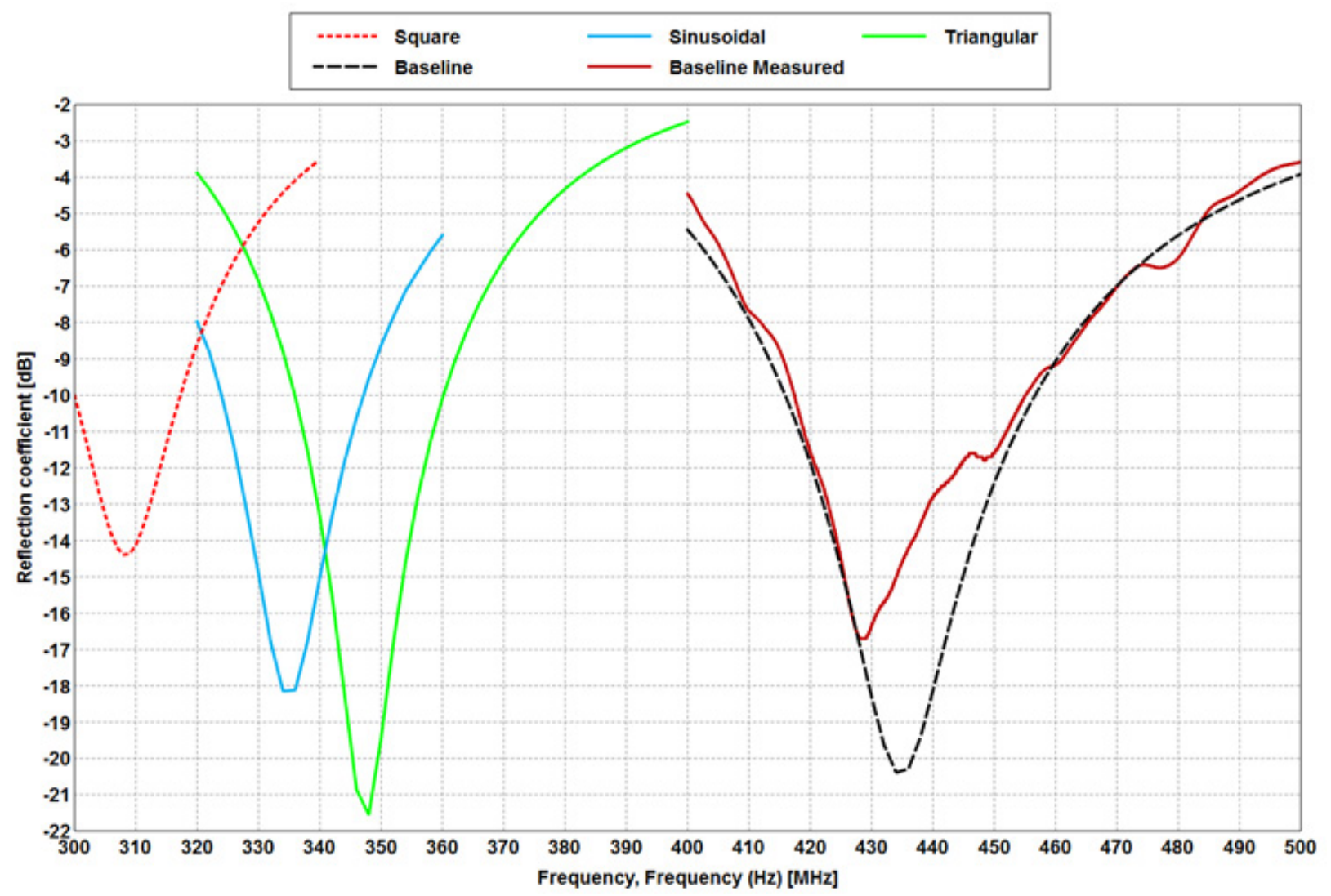

Fig. 5 Reflection coefficient for frequency-shifted meanders 


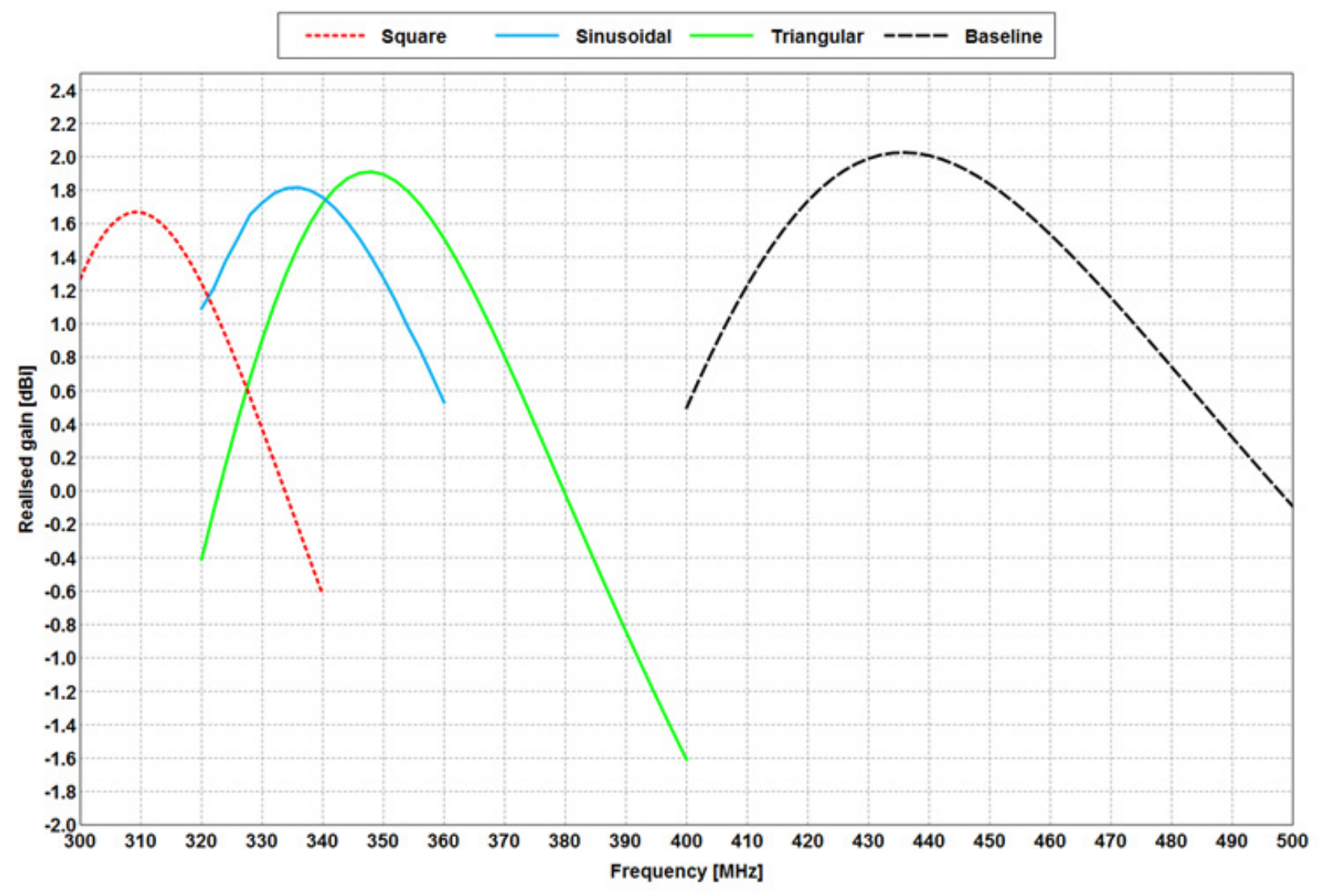

Fig. 6 Realized gain for frequency-shifted meanders

The sinusoidal meander results in a frequency shift not as large as that achieved by the square meander (23.04\%). Though the sinusoid may not have reduced the frequency by as much as the square, it does help to remove some of the field cancelations that were present in the square. The bandwidth does not decrease by as much as the square either (43.13\%), most certainly due to the smaller trace inductance and mutual capacitance. There is a reduction in the reflection coefficient $(2.24 \mathrm{~dB})$ and a loss in realized gain $(0.21 \mathrm{dBi})$ - still an improvement over the square meander. The triangular meander possesses the smallest frequency shift (19.82\%), but shows the smallest reduction in realized gain $(0.12 \mathrm{dBi})$ and bandwidth $(40.51 \%)$, and improves the reflection coefficient (1.16 dB additional).

Taking the percentage in frequency shift and applying it to the respective meandered structures in order to reduce their sizes results in corresponding resonances that are near the baseline mode (Figs. 7, 8, and 9). From here it can be shown that the previous trends of additional loss (square and sinusoidal), reduced loss (triangular), and reduced realized gain reduction (sinusoidal and triangular) still hold true. Here bandwidth reductions seem to be more structurally dependent showing that meandering results in bandwidth loss (22.37\% for square, $12.9 \%$ for sinusoidal, and $16.0 \%$ for triangular). See Table 1 for the square meander dimensions and Tables 2 and 3 for the comprehensive results. 


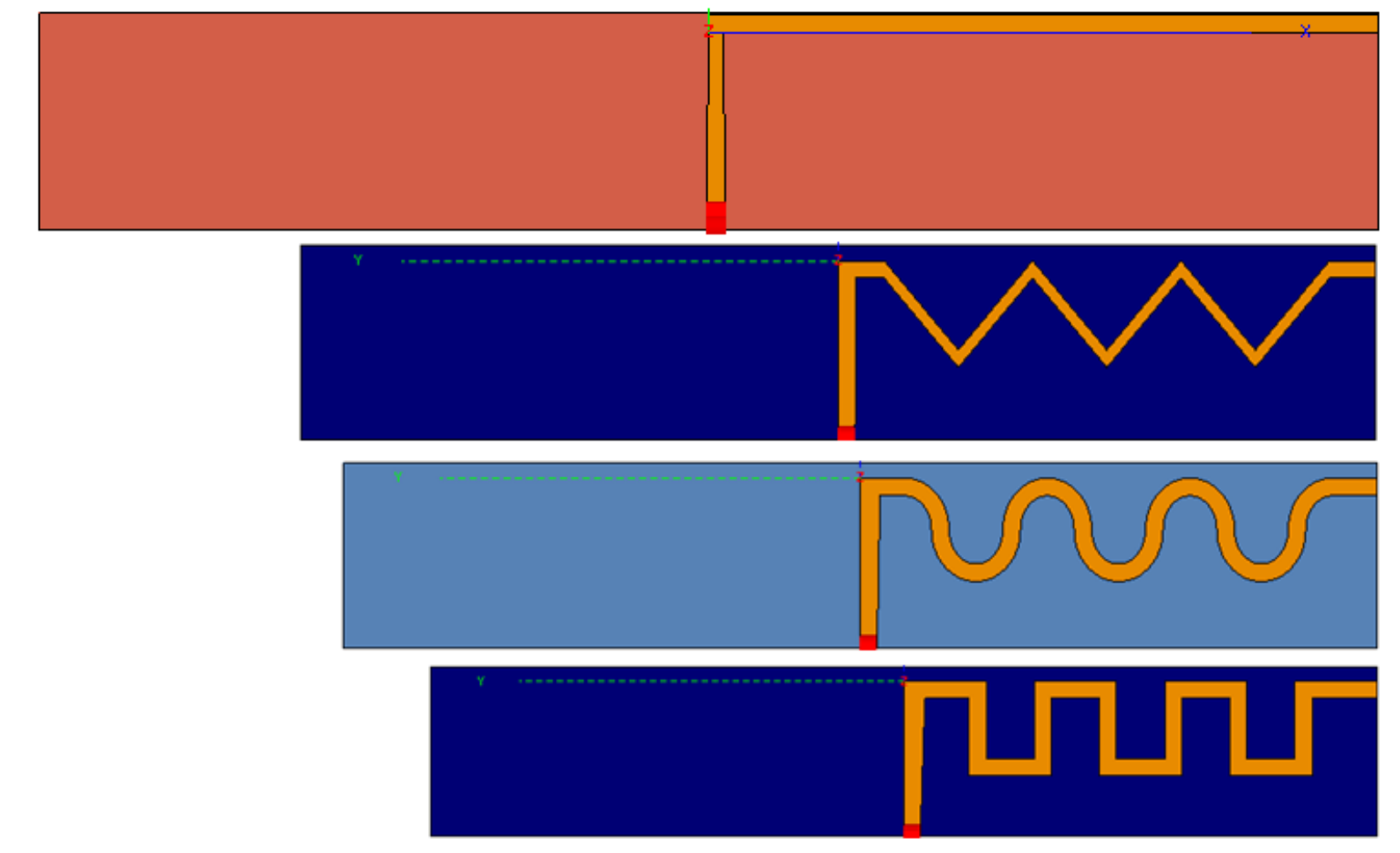

Fig. 7 Size reduction comparisons (not to scale)

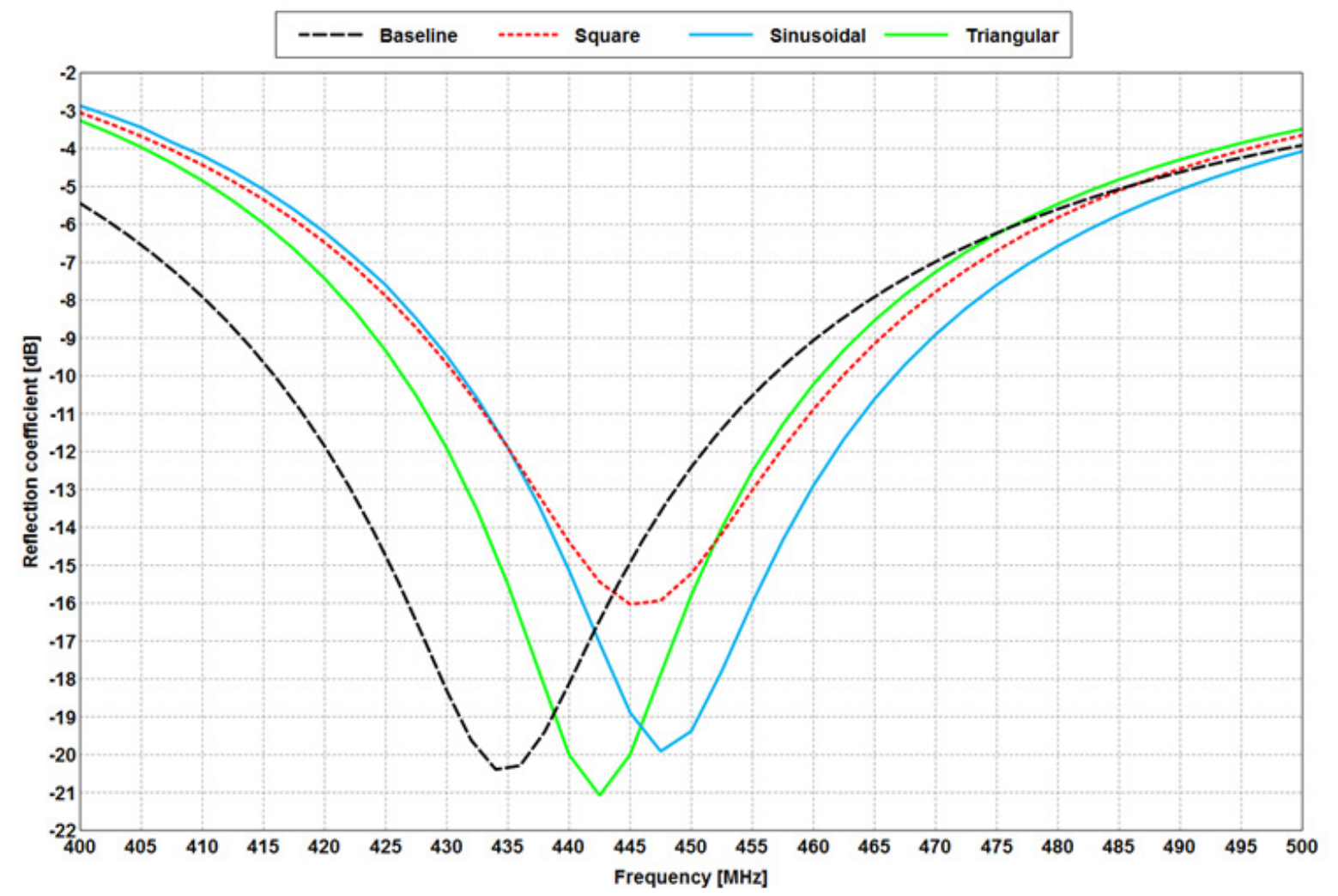

Fig. 8 Reflection coefficient for reduced-size meanders 


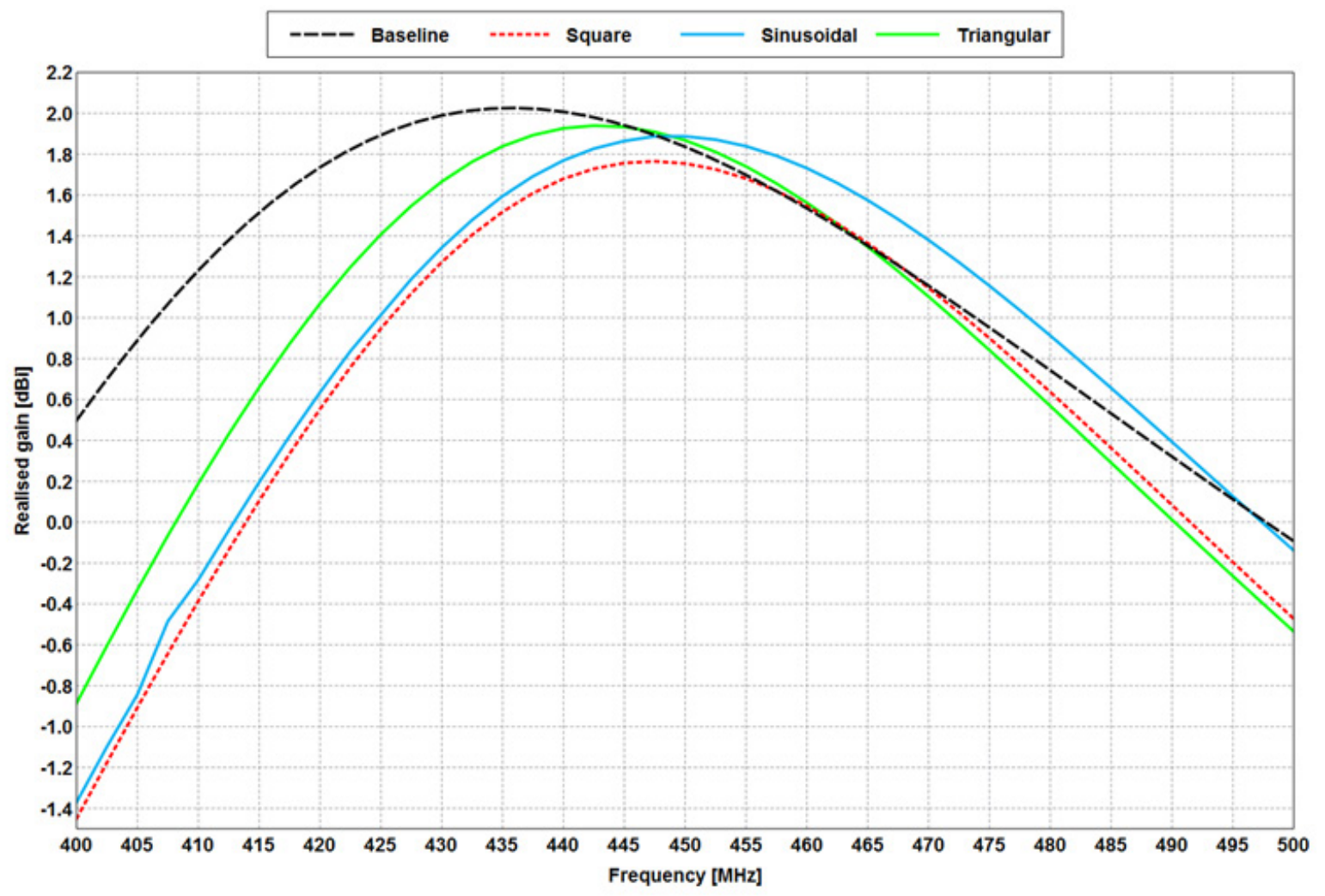

Fig. 9 Realized gain for reduced-size meanders

Table 1 Dimensions for the frequency-shifted square meander

\section{Square Meander Dimensions}

Total Board Length

$305 \mathrm{~mm}$

Total Board Width

$53.5 \mathrm{~mm}$

Number of Meanders " $\mathrm{N}$ "

Total Arm Length "L"

$334.9 \mathrm{~mm}$

Mechanical Arm Length "H"

$154.2 \mathrm{~mm}$

Trace Width "d"

$4.0 \mathrm{~mm}$

Meander Width "w"

$30.42 \mathrm{~mm}$

Meander Length "I"

$25.2 \mathrm{~mm}$

Substrate Thickness

$1.5748 \mathrm{~mm}$

Stripline Width [50 ohms]

$3.824 \mathrm{~mm}$

Stripline Width [meander]

$5.454 \mathrm{~mm}$

Ground Plane Width

$10.0 \mathrm{~mm}$

Substrate Overhang

$3.5 \mathrm{~mm}$ 
Table 2 Simulation results for the frequency-shifted meander results

\begin{tabular}{l|rr|r|r|}
\multicolumn{1}{c|}{$\begin{array}{c}\text { Structure } \\
\text { Struency } \\
{[\mathrm{MHz}]}\end{array}$} & $\begin{array}{c}\text { Reflection } \\
\text { Coefficient }[\mathrm{dB}]\end{array}$ & \multicolumn{2}{c|}{$\begin{array}{c}\text { Bandwidth } \\
{[\mathrm{MHz}]}\end{array}$} & \multicolumn{2}{c|}{$\begin{array}{c}\text { Realized Gain } \\
{[\mathrm{dBi}]}\end{array}$} \\
\hline Baseline & 434 & -20.39 & 40.76 & 2.03 \\
\hline Square & 308 & -14.39 & 19 & 1.67 \\
Sinusoidal & 334 & -18.15 & 23.18 & 1.82 \\
\hline Triangular & 348 & -21.55 & 24.25 & 1.91
\end{tabular}

Table 3 Simulation results for the reduced-size meanders results

\begin{tabular}{l|r|r|r|r|r|}
\multicolumn{1}{c}{ Structure } & $\begin{array}{c}\text { Frequency } \\
{[\mathrm{MHz}]}\end{array}$ & $\begin{array}{c}\text { Reflection } \\
\text { Coefficient } \\
{[\mathrm{dB}]}\end{array}$ & $\begin{array}{c}\text { Bandwidth } \\
{[\mathrm{MHz}]}\end{array}$ & $\begin{array}{l}\text { Realized Gain } \\
{[\mathrm{dBi}]}\end{array}$ & $\begin{array}{c}\text { Size } \\
\text { Reduction }\end{array}$ \\
\hline Baseline & 434 & -20.39 & 40.76 & 2.03 & N/A \\
\hline Square & 445 & -16.03 & 31.64 & 1.77 & $29.03 \%$ \\
\hline Sinusoidal & 447.5 & -19.91 & 35.5 & 1.89 & $23.04 \%$ \\
\hline Triangular & 442.5 & -21.08 & 34.22 & 1.94 & $19.82 \%$ \\
\hline
\end{tabular}

\section{Conclusion}

This report explored the impact that 3 different meander trace structures (square, sinusoidal, and triangular) can have on size reduction (frequency shift), reflection coefficient, bandwidth, and realized gain. The results show that the square meander is the preferred method for size reduction, but it can severely negatively impact the gain, reflection coefficient, bandwidth, and realized gain. The sinusoidal meander results in a more manageable reduction in bandwidth and realized gain but increases the reflection coefficient. The triangular meander improves the reflection coefficient and nearly maintains the realized gain of the baseline, but has the least impact on size reduction. Ultimately, the particular design requirements determine which meander structure should be used. 


\section{References}

1. Estrada JG, Paez C I. Design formulas for a meandered dipole. IEEE Xplore Digital Library, 2014: n. pag. Web. 2 September 2014.

2. Nguyen, VH, Phan, HP, Hoang MH. Improving radiation characteristics of UHF RFID antennas by zigzag structures. IEEE Xplore Digital Library, 2014: n. pag. Web. 2 September 2014.

3. FEKO. www.feko.info [Accessed 2 September 2014.]

4. Olaode OO, Palmer WD, Joines WT. Characterization of meander dipole antennas with a geometry-based, frequency-independent lumped element model. IEEE Xplore Digital Library, 2014: n. pag. Web. 2 September 2014.

5. Olaode OO, Palmer WD, Joines WT. Effects of meandering on dipole antenna resonant frequency. IEEE Xplore Digital Library, 2014: n. pag. Web. 2 September 2014.

6. Stutzman WL, Thiele GA. Antenna theory and design. Hoboken: John Wiley \& Sons Inc., 2013. Print.

7. McCormick SA. Planar dipole input resistance vs. trace thickness for different materials. Adelphi (MD): US Army Research Laboratory (US). Report No.: ARL-TN-0634. 


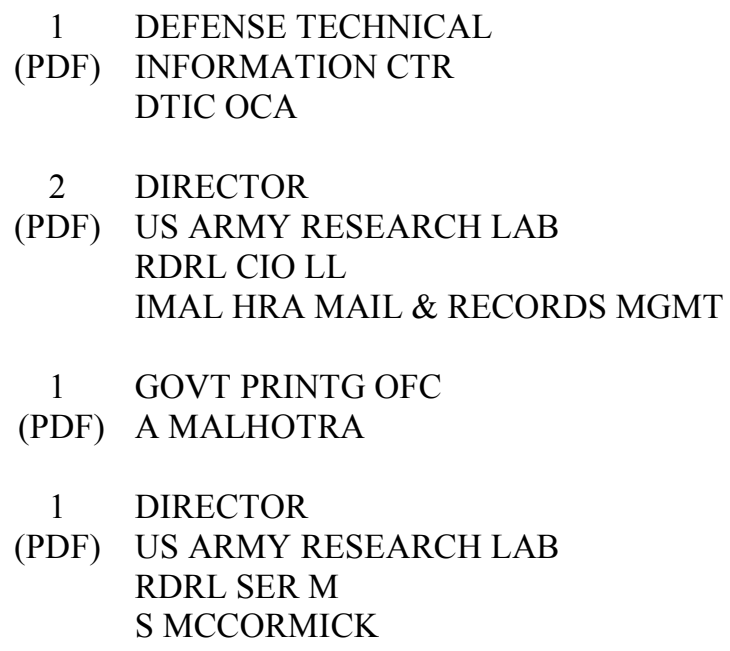


INTENTIONALLY LEFT BLANK. 